
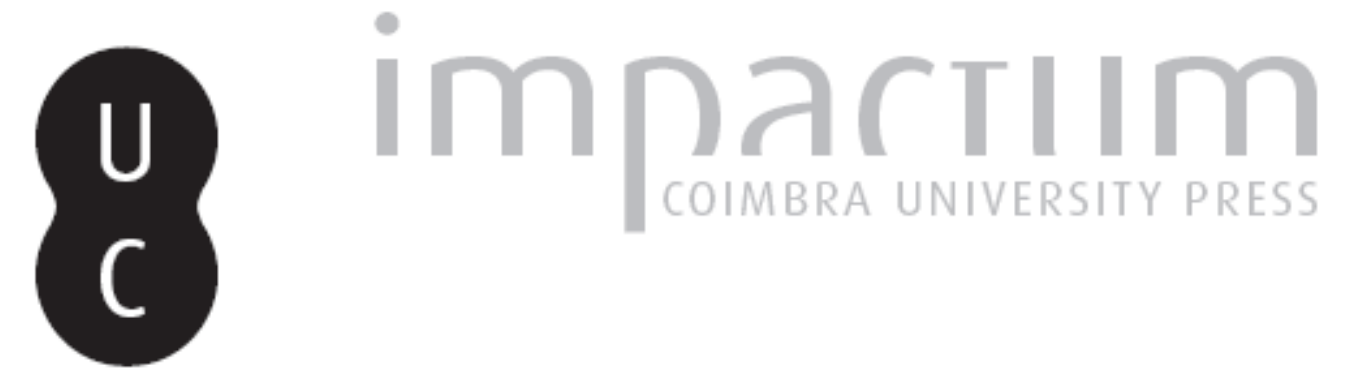

\title{
O cruzamento de culturas em Ausónio
}

Autor(es): $\quad$ Silva, Manuel Augusto Naia da

Publicado por: $\begin{aligned} & \text { Associação Portuguesa de Estudos Clássicos; Instituto de Estudos } \\ & \text { Clássicos }\end{aligned}$

URL

persistente:

URI:http://hdl.handle.net/10316.2/30308

DOI:

DOI:http://dx.doi.org/10.14195/0872-2110_56_4

Accessed : $\quad$ 26-Apr-2023 09:15:34

A navegação consulta e descarregamento dos títulos inseridos nas Bibliotecas Digitais UC Digitalis, UC Pombalina e UC Impactum, pressupõem a aceitação plena e sem reservas dos Termos e Condições de Uso destas Bibliotecas Digitais, disponíveis em https://digitalis.uc.pt/pt-pt/termos.

Conforme exposto nos referidos Termos e Condições de Uso, o descarregamento de títulos de acesso restrito requer uma licença válida de autorização devendo o utilizador aceder ao(s) documento(s) a partir de um endereço de IP da instituição detentora da supramencionada licença.

Ao utilizador é apenas permitido o descarregamento para uso pessoal, pelo que o emprego do(s) título(s) descarregado(s) para outro fim, designadamente comercial, carece de autorização do respetivo autor ou editor da obra.

Na medida em que todas as obras da UC Digitalis se encontram protegidas pelo Código do Direito de Autor e Direitos Conexos e demais legislação aplicável, toda a cópia, parcial ou total, deste documento, nos casos em que é legalmente admitida, deverá conter ou fazer-se acompanhar por este aviso.

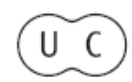




\section{Boletim de \\ Estudos Clássicos}

Associação Portuguesa de Estudos Clássicos Instituto de Estudos Clássicos

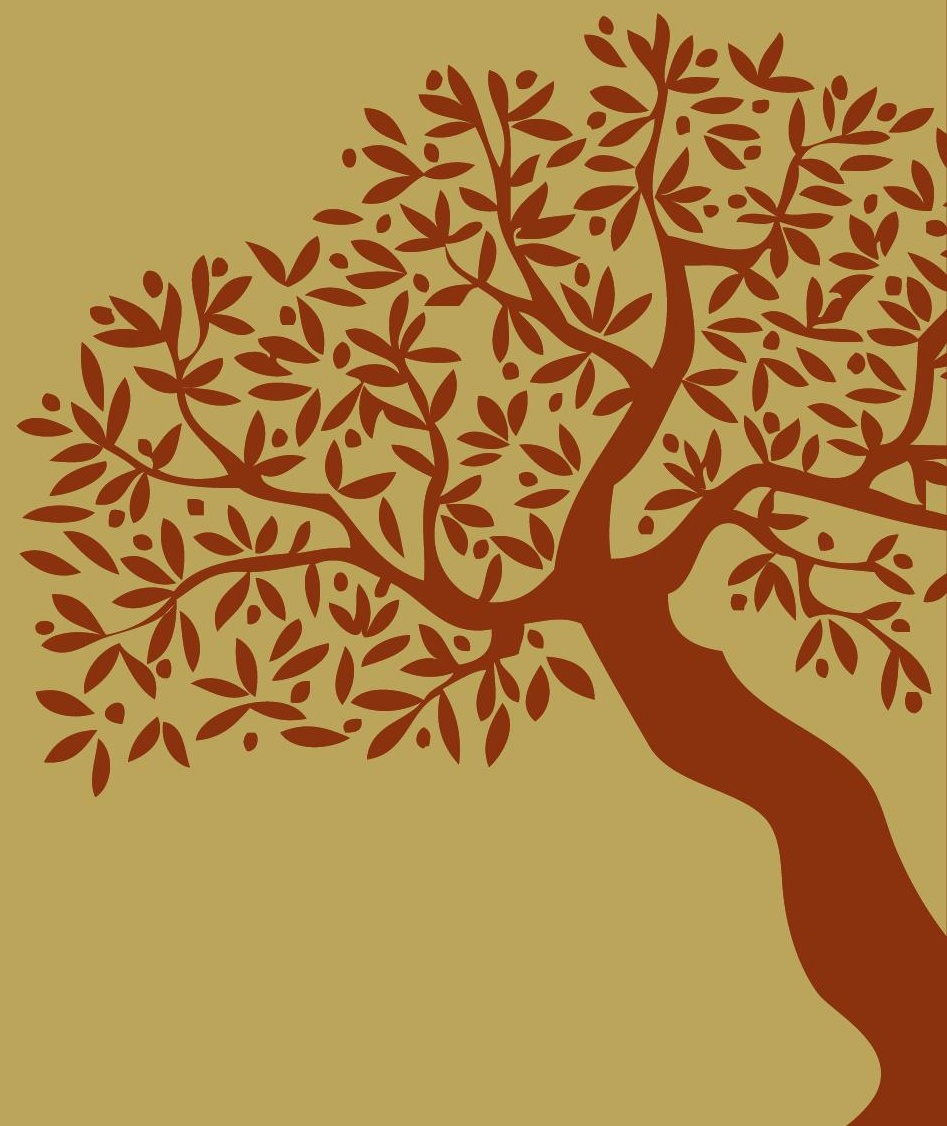

Coimbra

Dezembro de 2011 


\section{O Cruzamento de Culturas em Ausónio}

Como figura representativa do séc. IV, Ausónio deixa para trás um período de graves dificuldades no mundo cristão até ao dia em que as invasões bárbaras retomem incidências semelhantes.

Decimus Magnus Ausonius (310-393) nasce em Bordéus, mas, ainda jovem, fixa-se em Toulouse, onde recebe lições de um mestre que era seu tio. Com 24 anos inicia a sua vida profissional como "grammaticus" na Universidade. Depois, ensina retórica. Esporadicamente também se dedicou à advocacia. A morte da mulher inspirou-lhe o que melhor fez de poesia, quase sempre em composições de formato reduzido.

Depois de três décadas de ensino de gramática e de retórica, torna-se responsável pela educação do futuro imperador Graciano. Participa na campanha contra os Germanos e, com a subida do príncipe ao poder, a sua influência aos mais diversos níveis atinge o apogeu com o consulado, proporcionando, também por isso, a ascensão social de alguns familiares. Tudo muda com a morte de Graciano: volta à pacatez da sua terra natal para gerir os bens patrimoniais até morrer com mais de oitenta anos.

A primeira colectânea de textos foi de iniciativa do próprio Ausónio. Após a sua morte, foi o filho quem se encarregou da edição dos seus poemas.

$\mathrm{O}$ que verdadeiramente nos interessa aqui acentuar é que, aos 55 anos, dá-se a sua conversão ao cristianismo, mas tal não se pode afirmar sem mais. É que, ao longo dos tempos, tornou-se uma figura controversa exactamente por esse motivo ${ }^{1}$.

Tentaremos uma breve análise das composições que possam reflectir esta situação pessoal do autor. Não se afigura uma tarefa fácil traçar um retrato definitivo das opções culturais e religiosas em campos diferentes: a

${ }^{1}$ Basta citar alguns autores que o designam, sob este aspecto, de diversos modos: "half-believer" (in H.G.EVELYN WHITE, Ausonius I, Loeb C. L., 1988 (reimp.), p. XIV); praticante da "fé oficial" (in PARATORE, E., História da Literatura Latina, trad. port., Lisboa, Gulbenkian, p. 917); "cristiano solo de nombre" (in CURTIUS, E.R., Literatura europea y Edad Media Latina (2), trad. esp., México, F. C. Económica, 1995, p. 597); "honnête chrétien" (in BAYET, J., La Littérature Latine («Collection U»), Paris, A. Colin, 1965, p. 465). 
cultura romana e a ainda recente fé cristã. Os comentários aos textos vão no sentido dessa clarificação.

Escolhemos dois tipos de poemas ao nível dos seus conteúdos.

O primeiro diz respeito ao conceito da divindade até ao reconhecimento de Cristo dentro do quadro do Deus Uno e Trino; o segundo acrescenta à pessoa e à mensagem de Cristo o teor de vida comunitária dos cristãos, assente na prática do baptismo, um dos aspectos que certamente poderá indiciar com maior clareza a possível mudança do poeta para a nova religião.

I.

Começamos com um breve poema sob a epígrafe "Egressio", na edição utilizada $^{2}$. É evidente, logo de início, que está subjacente uma atitude de prece, de procura de alguma protecção numa força superior. No entanto, o conceito de Deus aparece num quadro de afirmação de fé monoteísta na melhor das hipóteses. Efectivamente, o quadro em que se invoca a divindade - "deo" (vs. 1), "numinis" (vs. 3) - não passa de uma circunstância banal da vida quotidiana, mas que prende a atenção: a solicitação de uma veste adequada a uma situação concreta, aos cuidados da cozinha, o que denuncia também o contraste entre o indivíduo e a sociedade. O destinatário desta petição - "puer" (vs. 4) - implica uma determinada estratificação do tecido social. Diferente é o contexto do epicédio dedicado por Ausónio a seu pai ${ }^{3}$. No prólogo, o lado humano do acontecimento - a morte do seu progenitor enquadra uma outra ordem de valores que coloca a divindade em primeiro lugar: "post deum". Por este motivo, cabe ao ascendente o segundo lugar pelo respeito e veneração que lhe são devidos: "secundam reverentiam"4.

Um conceito tão reduzido da divindade encontra noutros poemas um alargamento considerável. Num contexto moralista, citemos a «Oratio Paulini ${ }^{5}$. Esta personagem, que havia de ficar para a posteridade com o nome de "Paulino de Nola", tinha sido discípulo de Ausónio, a quem, aliás,

2 Seguimos os títulos inseridos na edição de H.G.EVELYN WHITE, op. cit., (esta composição: I, p. 22).

3 Id., I, p. 40.

4 A aceitação do vs. 8 sob a lição sugerida [cursum citatis sub equis] remeternos-ia para um contexto mitológico - o carro do sol movido por cavalos sob o comando de Aurora - , um quadro cultural que Ausónio parece nunca abandonar, mesmo disperso entre valores cristãos que enuncia e talvez perfilhe.

5 Id., II, p. 148. 
este não deu acordo quanto ao seu empenhamento religioso e cristão. Mais um aspecto questionável da posição religiosa de Ausónio ao recusar-se a acompanhar a evolução espiritual do discípulo. A composição vale pela invocação (vs. 1-2) e pelo dístico final (vs. 18-19). No primeiro caso, o registo de um deus todo-poderoso ("omnipotens"/ "summa potestas"), origem de todas as coisas, de tudo criador ("genitor rerum"), susceptível de atender os humanos nos seus justos pedidos ("si iusta precor"). O corpo intermédio do poema é constituído por um conjunto de intenções na perspectiva de uma religião natural e moralista. $O$ dístico final enuncia um deus que sabe recompensar o que de bem se faz na vida - "Moribus haec castis tribuit deus" - , que tem como bem último a vida eterna: "perpetuam vitam”. Não se chega, pois, a qualquer aspecto específico do cristianismo. A vida, a personalidade e a mensagem de Cristo, assim como qualquer registo bíblico explícito, estão claramente ausentes.

No poema "Oratio"6 assume-se um conceito mais definido da divindade numa moldura cristã. Com efeito, já é possível descobrir a menção das "três pessoas divinas": "pater" (vs. 31, 43, 58) acrescida de "Omnipotens" (vs. 1), "genitor (vs. 49); "nate" (vs. 27, 79); "spiritus" (vs. 48).

A primeira invocação do poema - "Omnipotens" - desenvolve uma série de referências próprias do "Filho" em relação com o "Pai"7 Além disso, são enumerados alguns atributos ("verbum", "deus”, "anticipator", vs. 9), assim como registos de eventos: a morte de Cristo com as incidências do sofrimento (vs. 21-22) e da sepultura (vs. 24-26) ${ }^{8}$.

Dentro da estrutura do texto, esta primeira parte (vs. 1-30) termina com uma invocação ao "Filho" ("nate", vs. 27) que assume a função de intercessor, de medianeiro relativamente ao "Pai", situando-se, por isso, entre Deus e o Homem. É perceptível que esta invocação tenha sido preparada pelos versos anteriores e de, alguma forma, se proponha retomar o seu conteúdo.

A parte restante do poema (vs. 31-85) desenvolve-se progressivamente, até, de novo, achar sequência num outro excerto com função semelhante, dirigido também ao "Filho" ("nate", vs. 80). Estes dois excertos (vs. 27-30 e

6 Id., I, pp. 16-22.

7 Vs. 7: "patriam propter considere dextram".

Vs. 21: "quo numine viso/ patrem vidisse datum".

8 De entre estas referências bíblicas a Cristo emergem as que são suscitadas pelo "Evangelho de S. João", v.g.: "per quem facta omnia" (vs. 13). 
79-85) proporcionam uma delimitação clara dentro da estrutura do poema. Numa primeira secção desta segunda parte (vs. 35-57), as preces desenvolvem-se num contexto da existência do pecado (vs. 31-36), da eternidade (vs. 37-42), do culto (vs. 43-57). Depois destas referências fundamentalmente de ordem religiosa, o orante deseja realizar nele próprio o que acaba de registar (vs. 58):

\section{"Da, pater, haec nostro fieri rata vota precatu"}

A invocação final (vs. 79-81) recupera uma série de epítetos atribuídos ao "Filho".

Tudo isto nos faz concluir que a centralidade do poema radica nas funções do "Filho" dentro do enquadramento religioso do cristianismo. Tratase de um aspecto fundamental na análise das opções religiosas do poeta. Neste caso, poder-se-á questionar a assunção pessoal de todos estes valores por parte do autor.

Outros dois quadros culturais - mitológico e bíblico (Velho Testamento) - estão presentes, respectivamente, nas referências a "Eous" (vs. 12), "manes" (vs. 57) e a "Aevvam", "serpens" (vs. 33), "Adam" (vs. 34), "anguis" (vs. 36), "Elias", "Henoch" (vs. 42), "David" (vs. 84). Uma análise mais aprofundada deste poema ao nível dos critérios da intertextualidade proporcionaria o encontro com outros escritos neo-testamentários.

Citemos, por fim, o poema "Griphus Ternarii Numeri", verseja à volta da aplicação do número três nas mais diversas incidências.

Depois de referir, no primeiro verso, que tal número encerra um valor místico - "sic mystica lex est" - , alonga-se na apresentação das circunstâncias assentes nessa grandeza, acabando por criar um círculo à volta da afirmação do acto de beber com que começa e põe termo à composição: "ter bibe". Esta atinge ainda o seu fim com a referência ao número de versos do poema - noventa - também divisível pelo número três. Mas o que nos interessa realçar é que, ao terminar a série de aplicações do número três, o autor apresenta a que enquadra o próprio Deus:

\section{"tris numerus super omnia tris deus unus."}

É evidente que se trata de uma mera referência à Trindade das pessoas do Deus cristão, mas diríamos também adequada, por exemplo, à tríade capitolina (Júpiter, Juno e Minerva).

Um quadro como este, de grande distanciamento entre o poeta e o poema, é tido como uma das características dominantes da personalidade de

$$
{ }^{9} \text { Id., I, pp. 358-369. }
$$


Ausónio: "mecânico e complacente"10, predominantemente descritivo, preso ao exterior, às primeiras impressões - por este motivo, "Mosella" é a composição apontada como a sua obra-prima, além de ser a mais extensa ${ }^{11}$ - , avesso ao discurso introspectivo e propenso à indiferença pessoal face às realidades que tem de enfrentar. Em sentido contrário, porém, parece situar-se o poema intitulado "Parecbasis"12. É a retoma de uma situação similar à do poema "Egressio", em que entra em cena o convívio resultante das obrigações entre um senhor e um serviçal ("puer"). Trata-se, como o título sugere, de uma "digressão", de um registo passageiro, que, neste caso, ao mesmo tempo que cita as pessoas da Trindade ${ }^{13}$, descreve também uma atitude vivencial. Realça a interioridade do crente perante o que é exterior. Dentro desta linha, recusa tudo o que faz parte da materialidade cultual, como o incenso ("tus", vs. 11), os bolos ("liba crusta mellei", vs. 12) e os locais familiares ("foculum", vs. 13) onde se realizam os sacrifícios. Por outro lado, é realçada toda a vivência interior: as preces (" pia verba, vota innoxia”, vs. 9), assim como a manifestação do sentimento, nomeadamente do temor ("sentit pavens", vs. 21) diante do transcendente ("cogitatio numinis", vs. 20). Tal introspecção é encarecida quando é enunciada a obrigação de prestar culto a Deus na primeira pessoa: "Deus precandus est mihi" (vs. 15). Além disso, a crença no monoteísmo, a oposição à existência dos deuses doutras religiões, parece por vezes ser algo não muito claro quanto às opções de Ausónio. Aqui, porém, afirma a vacuidade do culto dos deuses recusando-o peremptoriamente: "vanis relinquo altaribus" (vs. 14). Ora é sabido como foi grande a resistência de algumas gerações de cristãos dos primeiros séculos em romperem definitivamente com o culto aos deuses pagãos ${ }^{14}$.

\footnotetext{
${ }^{10}$ Id., I, p. XXVI.

${ }^{11}$ Id., I, pp. 224-262.

12 Id., I, p.14.
}

13 "Deus" (vs. 15); "filius summi Dei” (vs. 16); "sacro spiritu" (vs. 17).

14 A este propósito, é de referir, por exemplo, a mensagem e os conselhos de Martinho de Braga dirigidos, ainda no séc. VI d. C., ao bispo de Astorga sobre a prática de superstições que não escapavam à própria idolatria (vd. Instrução Pastoral sobre Superstições Populares De Correctione Rusticorum, Lisboa Edições Cosmos, 1997). 
II.

A segunda série dos poemas da autoria de Ausónio não se limita ao registo de um conceito mais ou menos alargado sobre Deus, mas entra em aspectos da vivência dos cristãos, em grupo ou comunidade, como também numa, embora reduzida, afirmação do nome e da pessoa de Cristo.

Abordaremos duas composições dentro deste quadro da assunção da fé cristã nos primeiros séculos.

O poema redigido em hexâmetros e intitulado "Versus Paschales pro Augusto dicti"15 inclui a referência (vs. 1, 6, 16, 20, 31) à Trindade de Deus ("pater" - "Christus" - "Spiritus") ${ }^{16}$, aliás, como registamos em composições anteriores, o que se revela peculiar na prática da vida dos cristãos.

Logo de início, o culto. Merece aturada atenção o primeiro par de versos:

\section{"Sancta salutiferi redeunt sollemnia Christi et devota pii celebrant ieiunia mystae."}

Daqui se conclui que:

- os actos de culto já são recorrentes no tempo: "redeunt"; além disso, eram celebrados com toda a solenidade: "Sancta [...] sollemnia";

- o sujeito e o objecto do culto eram cumulados de devoção intensa: "piae mystae", "devota ieiunia";

- a razão de tal culto é Cristo considerado como autor da salvação: "salutiferi".

Em segundo lugar, emerge um outro valor bem importante por fazer parte da raiz do cristianismo: a prática do baptismo. Começa o poema com um indício bem significativo: a importância dos iniciados - "mystae" (vs. 2) , fenómeno social característico dos primeiros anos sob a guarda da lei do arcano ou do segredo. O simbolismo da água, inerente ao culto do baptismo, aparece como uma nova vida oferecida à condição mortal, um reflexo da força criadora do que é denominado "espírito" que pairava sobre a extensão líquida segundo a versão bíblica da criação (vs. 20-21).

Por fim, algo que também atinge o cerne da fé cristã, a afirmação da eternidade: "aeternum cultum" (vs. 3), "Aeternae vitae" (vs. 11), "ab origine unum" (vs. 18), "speratae vitae" (vs. 23), "aeternum patrem" (vs. 31).

15 Id., I, pp. 34-38.

16 Os actos religiosos, que exprimem a interioridade, a devoção, têm como objecto, neste poema, a Trindade: "trina fides" (vs. 22), "trina pietate" (vs. 29). 
De realçar, ainda, neste poema (vs. 31) como num outro anterior ("Oratio", vs. 80), a mesma súplica subjacente à relação entre "Pai" e "Filho", variando apenas o vocábulo invocativo precedente em ambos ("nate", "Christe"). Na verdade, trata-se de alguém cuja capacidade de se condoer se torna garante da eternidade:

"aput aeternum placabilis adsere patrem"

Igualmente, nestes dois poemas, entrelaçam-se alusões mitológicas e bíblicas. Neste, em particular, registam-se "Tártara" (vs. 7) e "Adam" (vs. 14), "Aevva" (vs. 15). Por outro lado, a família do imperador e respectiva descendência apresenta-se como uma imagem ("specimen", vs. 24) da transcendência da Trindade de Deus. Mais uma vez, poder-se-á questionar o peso desta alusão no espírito do escritor.

O outro poema - "Oratio Consulis Ausonii"17 - avança um pouco mais nas referências à experiência de vida dos cristãos. Trata-se de um conjunto de versos designados "ropálicos", que se iniciam com monossílabos sendo os restantes vocábulos de cada verso dotados de uma sílaba a mais que o anterior. Recorre-se, evidentemente, ao preciosismo literário manifesto no uso de uma métrica artificial, bem característico neste autor, à míngua de inspiração genuinamente poética. Desta forma põe à prova a sua habilidade de versejador, em qualquer tempo ou lugar, com o intuito de dizer muito com escassez de meios.

Mas neste texto, o autor volta a temas já versados na composição anterior: "Trindade"18, "culto"19, "baptismo"20, "vida para além da morte"21. Por outro lado, acrescenta algo mais. É o caso da alusão a aspectos e realidades num quadro cristão: o baptismo de Cristo no rio Jordão (vs. 19), o evento da crucificação (vs. 25), o diálogo com o ladrão condenado e o

17 Id., I, pp. 38-40.

18 Relativamente ao "Pai": "pater" (vs. 3, 6), "rector" (vs. 16); ao "Filho": "Christo" (vs. 4, 21); ao "Espírito Santo": "paraclito" (vs. 7).

19 Realçando a experiência religiosa: "cultorum" (vs. 5); "devotio" (vs. 8); "ieiunia relligiosa" (vs. 13).

20 Referindo a água como base de uma regeneração espiritual: "fons", "recreatu" (vs. 16); "baptismatis" (vs. 22).

21 As invocações a Deus no início e no término conferem ao poema uma feitura circular: "aeternae stationis conciliator." Aliás, ambos os poemas terminam com uma prece veiculada quer pela denominação de "céu" ("caelum"), quer pela referência ao "Pai" ("aeternum patrem"). 
paraíso que lhe é prometido (vs. 35). Particularmente relevante é a apresentação do conjunto dos cristãos como estrutura organizada - como povo - sob a direcção dos seus mentores religiosos. O primeiro dos mártires cristãos, Estêvão, torna-se uma personagem decisiva e bem importante no revigoramento das primeiras comunidades. Por esse motivo, assume-se como uma porta aberta à relevância de Paulo que é apelidado, apesar de ter sido um dos instigadores dos que provocaram a morte de Estêvão por apedrejamento ${ }^{22}$ - "lapidantum constimulator" (vs. 34) - , de mestre do povo (“doctor populi", ibid.) e chefe religioso ("antistite relligionis", vs. 38). Não há dúvida de que não eram desconhecidas de Ausónio as incidências históricas mais relevantes que sustentavam a fé dos cristãos. Por fim, é ainda de referir o simbolismo da luz em contraste com a noite, com as trevas denunciadoras do mal e ainda a alusão à água (vs. 16, 19,22) e aos cordeiros (vs. 20), o que é performativo num quadro baptismal.

Uma leitura atenta dos poemas de Ausónio, dos que possam clarificar um pouco a sua posição face ao cristianismo, não nos liberta de uma certa perplexidade, se tentarmos descobrir qual a medida em que as duas culturas se entrecruzam no seu espírito. Estamos, pois, perante uma personalidade bifacetada, permeável a duas correntes de opinião. O confronto de duas culturas no dinamismo interior de uma única pessoa só parcialmente se torna perceptível no exterior, nomeadamente através da obra literária, muitas vezes de paredes-meias com a ficção. Ora o exterior, o que aparece à tona das suas qualidades de versejador, às suas capacidades descritivas indesmentíveis, não se apresenta de modo linear.

Literariamente Ausónio deve muito à inspiração clássica dos poetae noui do séc. I a. C., que rompem com a tradição e se revestem da roupagem alexandrina. A partir do séc. II d. C., os então designados poetae nouelli ou neotéricos optam por caminhos semelhantes. Por isso, não é de estranhar que ele enverede pelos mais variados metros em composições quase sempre de formato reduzido, entretendo-se, como que exercitando o engenho. É neste quadro que o autor desenvolve a sua opção pessoal. Aqui se pode aquilatar o peso anímico de uma informação substancial e verídica sobre Deus, Cristo e o culto dos cristãos em grupo ou comunidade, de que ele muito possivelmente fazia parte.

22 Act. VII.58-60. 
Como nos foi dado verificar, os poemas de Ausónio atingem conceitos de ordem religiosa a diversos níveis. E, por vezes, tudo parece igual! Neste sentido, particularmente relevante é o poema "Griphus", em que as muitas incidências do número três em temas não-cristãos se acotovelam até chegar à Unidade e Trindade de Deus. De facto, o problema é que estes conceitos acerca da divindade parecem nivelados a tudo o resto, reflectindo um certo afastamento, mesmo, até, a indiferença valorativa do autor! E se por aqui se ficasse, tudo se tornaria bem claro. Mas a verdade é que alguma vez havia de questionar a interioridade subjacente aos actos de culto (em "Parécbasis"). Por outro lado, são mais decisivas e prementes as informações sobre a vivência dos cristãos a propósito do baptismo, de acontecimentos fundamentais da vida de Cristo, do relevo concedido à celebração da Páscoa (em "Versus Paschales", "Oratio Consulis Ausonii"). Estes aspectos sobrelevam-se certamente a todos os outros que suscitam dúvidas. A par de tudo isto, um moralismo próprio de uma religião natural quando realça apenas um conceito incipiente acerca do que é divino (em "Oratio Paulini”). Uma textura mais complexa, no entanto, surge no poema "Oratio", porque assenta em textos bíblicos do Novo e Antigo Testamento, ao mesmo tempo que em alusões à mitologia. Pelos conteúdos que se cruzam, é de presumir que seja este o texto mais transparente e, por isso, de maior peso para avaliar a evolução espiritual do poeta.

No meio de todos estes dados, torna-se razoável presumir que a opção pessoal de Ausónio é pelo cristianismo, de preferência à partilha exclusiva de uma outra cultura. Todos os seus escritos de inspiração clássica são contrariados, em medida superior, pelas informações sobre a vida dos cristãos e, por isso, supostamente assumidas em reuniões de grupo, no seio de uma das comunidades cristãs. A par dos conhecimentos da Bíblia remanescentes em muitos dos seus versos, a linguagem sobre a vivência baptismal não engana facilmente, o que implica uma participação activa da sua parte. A referência ao culto pascal, elemento essencial da vivência dos cristãos, ultrapassa em muito o lastro cultural em que ele, de facto, terá sido educado. Não seria, pois, razoável que alguém, com estas alusões e experiências vividas bem de perto, passasse ao lado de uma afirmação de ordem pessoal e comprometida. No entanto, todos os outros poemas, os que não foram objecto deste estudo, navegam num outro mar, no fundo de uma outra cultura colhida no berço, que tão somente se entrecruza, no espírito de Ausónio, com o cristianismo ainda a experimentar os primeiros passos e, por isso, também a fazer-se cultura para os seus seguidores. Esse vasto campo da sua 
mundividência, registado em versos a propósito de tudo e de nada, gera em nós, talvez, uma sugestiva interpelação pela aparente convivência pacífica com valores não-cristãos, mas parece não apagar os versos determinados por uma outra inspiração, que veiculam o outro lado da sua cultura, das suas convicções, enfim, a sua opção pelo cristianismo a braços com o fervilhar de problemas dos primeiros séculos.

MANUEL AUGUSTO NAIA DA SILVA 